\title{
Observação de aves no Refúgio de Vida Silvestre Metrópole da Amazônia: uma contribuição para a conservação ambiental da unidade e ao desenvolvimento turístico do Estado do Pará
}

\section{Birdwatching in Life Refuge Silvestre Metropolis of the Amazon: a contribution to environmental conservation unity and tourist development of Pará State (Brazil)}

\author{
Maria do Perpétuo Socorro Rodrigues de Almeida, Mirleide Chaar Bahia, \\ Sherre Prince Nelson
}

\section{RESUMO}

As Unidades de Conservação, espaços protegidos por lei, vêm sendo mais requisitadas para diversas finalidades de uso, seja por turistas convencionais, seja pelas comunidades que residem nas imediações dessas áreas, ou ainda pela procura de atividades específicas, como é o caso dos observadores de aves, que colecionam avistamentos e enriquecem suas vidas com a contemplação desses animais, ao mesmo tempo em que colaboram para a ciência. A observação de aves ou birdwatching é uma atividade de recreação, fundamentalmente educacional, praticada ao ar livre, que prega os princípios da conservação ambiental. Este estudo teve como objetivo principal desenvolver uma proposta de implantação da atividade de Observação de Aves no Refúgio de Vida Silvestre (REVIS) Metrópole da Amazônia, Unidade de Conservação de Proteção Integral (estadual), localizada na Região Metropolitana de Belém, Pará, como instrumento de conservação ambiental, que possa contribuir para a auto sustentabilidade financeira da UC e de geração de renda para as comunidades locais. A pesquisa se caracterizou como um estudo qualitativo, com a utilização de alguns dados quantitativos, com mesclagem de pesquisa bibliográfica e de campo, e teve a contribuição de ornitólogos do Museu Paraense Emílio Goeldi, na validação das espécies avistadas e a confirmação da lista final. Teve como um dos resultados uma lista de avifauna atualizada com 202 espécies incluindo algumas endêmicas e em situação de risco, o que motiva o turismo de observação de aves, segmento que ainda desponta com timidez no Estado do Pará. Como contribuição para a gestão da Unidade de Conservação, são apresentadas alternativas de ações que devem ser realizadas para desencadear o ecoturismo de observação de aves no REVIS, com vistas a atingir o principal objetivo de criação da Unidade, que é a manutenção da vida silvestre, criando condições para a sua reprodução.

PALAVRAS-CHAVE: Áreas Protegidas; Unidades de Conservação; Observação de aves; Amazônia. 


\begin{abstract}
There is an increasing demand by tourists and nearby communities to frequent protected areas, which are protected by law. People with specific interests also search for protected areas, which is the case of birdwatchers who collect sightings and enrich their lives by enjoying birds, while at the same time contribute to science and the quality of the environement. Birdwatching is an educational recreational activity that occurs outdoors and encourages enviromental conservation. The main objective of this study is to develop a proposal for birdwatching in the Amazonian Metropolis Wildlife Refuge, an integrally protected area located in the urban region of the city of Belém, Pará, Brazil. The proposal will serve as an instrument for environmental conservation which can also contribute to its economic sustainability and offer an alternative income source for the local communities. This research project is primarily qualitative while also using quantitative data, bibliographic research and field work. Ornithologists from the Emelio Goeldi Museum contributed to it by confirming the species sighted and checking the accuracy of the bird lists. One of the results is a updated list of 202 species including several endemic species and those threatened with extinction, which is what motivated the introduction of birdwatching, a segment of tourism that is just beginning to occur in the state of Pará. Alternative activities are proposed for the success of ecotourism and as a contribuition to the protected area's administration which has the objective of maintaining wildlife and creating conditions for its reproduction.
\end{abstract}

KEYWORDS: Protected Areas; Conservations Units; Birdwatching; Amazon.

\title{
Introdução
}

O Refúgio de Vida Silvestre (REVIS) Metrópole da Amazônia é uma UC de Proteção Integral do Estado do Pará, categoria de manejo estabelecida pela Lei $\mathrm{n}^{\circ}$ 9.985, do Sistema Nacional de Unidades de Conservação (SNUC) que permite o uso público, e que tem como objetivo principal a manutenção da vida silvestre, criando condições para a sua reprodução.

O REVIS possui $6.367,27$ hectares de área e sua demarcação abrange quatro municípios da região da Grande Belém: Ananindeua, Marituba, Benevides e Santa Izabel. Com ecossistemas de floresta de terra firme, de várzeas, de igapós e de áreas de capoeira em recuperação, sendo um ambiente propício para a moradia e para a reprodução de muitas espécies de fauna, a UC está situada no Centro de Endemismo Belém.

Mesmo com diversas ameaças previstas para uma área de floresta próxima a um centro urbano, como principalmente a ocupação humana, de acordo com estudos realizados na ocasião da implantação desta Unidade de Conservação, ainda existe uma diversidade considerável de avifauna no local, o que suscita a prática da observação de aves, se constituindo como um importante instrumento de auxílio à divulgação de uma UC e da conservação ambiental de uma região. 
A observação de aves ou birdwatching, ou ainda birding, é uma atividade de recreação, fundamentalmente educacional, praticada ao ar livre, que prega os princípios da conservação ambiental, pois os praticantes (birdwatchers), além de colecionar os registros através de fotos, sonorização e outros vestígios, têm a possibilidade de fornecer dados sobre as observações para auxiliar em pesquisas e na gestão de áreas protegidas. A observação de aves está ligada diretamente ao ecoturismo, por suas características de preocupação com a conservação do ambiente visitado e de todo o ecossistema envolvido.

Essa modalidade é muito praticada no exterior, principalmente na Europa, nos Estados Unidos, no Japão e na Austrália, com uma estimativa de mais de oitenta milhões de pessoas se deslocando para observar aves em vários lugares do mundo. No Brasil, esta prática vem ganhando muitos adeptos, entretanto, o que se tem percebido é que no Estado do Pará, a atividade ainda é muito insipiente, por vários fatores que serão abordados ao longo deste trabalho.

Nesta pesquisa, a observação de aves é sugerida para o REVIS Metrópole da Amazônia, devido à constatação da ocorrência de mais de duzentas espécies de aves catalogadas na área, com grandes possibilidades de avistamentos. Também há significativa representatividade de endemismos e de espécies em risco, conforme registros sistematizados nos estudos realizados para a criação da UC.

Partindo-se desses pressupostos, este estudo teve como objetivo principal desenvolver uma proposta de implantação da atividade de Observação de Aves no Refúgio de Vida Silvestre Metrópole da Amazônia como instrumento de conservação ambiental, como possibilidade de auto sustentabilidade financeira da UC e de geração de renda para as comunidades locais.

Como trajetória de trabalho para se atingir tal objetivo, a pesquisa se caracterizou como um estudo qualitativo, com a utilização de alguns dados quantitativos, a fim de se demonstrar a viabilidade de implementação desta atividade na UC como um segmento do ecoturismo e como uma ferramenta de educação ambiental, a ser aplicada, tanto para as comunidades do entorno, quanto para os visitantes da UC.

A pesquisa bibliográfica não se esgotou à primeira fase do trabalho levantamento de dados secundários, mas se estendeu até os últimos momentos da sistematização desta pesquisa, principalmente no que se refere às consultas e aos sites sobre aves e sobre as experiências de observação de aves no Brasil e no mundo.

Foram consultadas fontes sobre Uso Público em Unidades de Conservação de Proteção Integral, estudos de casos, lista de espécies da avifauna local, lista de espécies em risco ou ameaçadas, estatísticas sobre turismo de observação de aves, além de outros documentos relacionados.

Para a realização do levantamento que resultou na lista atualizada do REVIS, foi firmada uma parceria (não formal) com alguns pesquisadores do Museu Paraense Emílio Goeldi, estudantes de Mestrado e Doutorado em Zoologia. 
Após algumas visitas a campo para o reconhecimento da área, foram definidas algumas trilhas já existentes na UC, porém por muito tempo sem uso, que serviriam para a escuta e registro das aves, evitando-se dessa a abertura de novas trilhas, o que resultaria em mais impacto e intervenção nos recursos. Para a marcação das trilhas foram utilizados GPS Etrex 30, caderneta de campo e fita zebrada (para fixação nas árvores). Em todas as investidas a campo os pesquisadores foram acompanhados por um "mateiro", morador do REVIS e por dois militares do Batalhão de Polícia Ambiental.

Com base na pesquisa bibliográfica e nos resultados da pesquisa de campo pelos pesquisadores do Museu Goeldi, foi elaborada uma lista preliminar de espécies para o REVIS, o que subsidiou a proposta da implantação de infraestrutura de observação na Unidade de Conservação. Essa lista foi estudada e validada por Aleixandre Aleixo, pesquisador ornitólogo, do Museu Paraense Emílio Goeldi e editor da Revista Brasileira de Ornitologia que, além da validação, observou as espécies mais interessantes e que podem mover um público de observadores de aves.

A metodologia aplicada nesse caso foi a de busca ativa, que consiste em percorrer o maior numero possível de ambientes no intuito de realizar registros quantitativos do maior número de espécies de aves. Para auxiliar a busca, foram utilizados binóculos 10X42, gravador digital (Marantz PMD660), microfone (Seinnheiser ME66), equipamento para playback (Ipod + caixa reprodutora de som) e máquina fotográfica. As gravações e fotos não identificadas foram identificadas com auxilio de acervos on-line. A equipe seguiu os transectos previamente determinados para o registro das espécies (avistamento, vocalização e outros vestígios).

As informações coletadas foram registradas em cadernetas de campo e posteriormente transcritas para compor a lista. Não houve coleta de nenhum material biológico para esta pesquisa. Para a confirmação de algumas espécies da lista, os pesquisadores do Museu Goeldi utilizaram dados de coletas que haviam sido feitas na área anteriormente.

Os trabalhos de campo realizados na UC foram feitas por meio de visitas técnicas em toda a área. Foram percorridos em média, a pé, aproximadamente 120 quilômetros no interior do REVIS, somando todas as investidas a campo; e de carro, aproximadamente 50 quilômetros. Para os percursos de carro foi utilizado veículo de tração - Caminhonete Chevrolet S10, para vencer as dificuldades de acesso decorrentes de lama e estradas sem condições.

Com base nas estatísticas e durante o reconhecimento da área do REVIS, foram levantadas as necessidades da estrutura das quais a UC precisa ser dotada para que a atividade possa ser implementada. Essas necessidades envolvem uma série de requisitos como infraestrutura física de apoio ao visitante, envolvimento e capacitações de pessoas das comunidades residentes e do entorno, parcerias com instituições de ensino e outras que possam contribuir para a divulgação do REVIS como destino de observação de aves. 


\title{
Uso Público em Unidades de Conservação
}

A utilização das áreas naturais para atividades de turismo, recreação, prática de esportes e atos religiosos é antiga e vem crescendo nos últimos anos por conta da carência de espaços públicos naturais, devido ao avanço populacional das cidades e bairros. Seja qual a motivação dessa busca, as Unidades de Conservação sempre são oportunidades para conhecer e valorizar os seus recursos, cuja estrutura deve ser adequada para a visitação e prática dessas atividades.

Em Unidades de Conservação o termo "Uso Público" é utilizado sob vários pontos de vista e com diferentes enfoques, dependendo da categoria de manejo da UC, porém as principais motivações que levam à utilização do termo têm a ver com turismo, lazer e recreação.

\begin{abstract}
O uso público pode se dar de várias formas e engloba toda atividade que pode ser desenvolvida na UC, dependendo, obviamente, de sua categoria e zoneamento. Pode ser turismo, visitas educativas, educação ambiental, pesquisa, entre outras. Os visitantes podem ir em grupo, ou sozinhos; podem ser de países diferentes ou de uma escola próxima; podem ser idosos ou jovens; podem ter ou não dificuldades de se locomover, escutar ou ver, e assim por diante. O ideal da visitação, de uma forma geral, é que ela seja aberta a todos, independentemente dos seus desafios e habilidades (NELSON, 2012, p.216).
\end{abstract}

Os termos uso público e recreação, quando relacionados às áreas naturais, são utilizados para definir o uso e as atividades desenvolvidas nestes locais. A recreação consiste em atividades de diversão praticadas durante o tempo livre e é o termo adotado na linguagem técnica internacional pelos especialistas em lazer. Este termo, que foi adotado pelos órgãos oficiais, ligados ao manejo das áreas naturais protegidas no Brasil, pode ser definido como o usufruto gozado pelo público, quer seja recreacionista, educador, pesquisador ou religioso (MAGRO, 1999).

O Decreto Federal o 84.017, de 21/09/1979, que aprovou 0 Regulamento dos Parques Nacionais Brasileiros e definiu as condições e restrições básicas de uso público, foi o primeiro documento editado para tratar de visitação em Unidade de Conservação. A partir daí, foram tomadas outras iniciativas com a finalidade de ordenar o turismo que, na época, era tratado com a denominação de "turismo ecológico".

Sobre a utilização das Unidades de Conservação pelo público, Nelson (2012, p.215), ratifica como "uma maneira de aproximar as pessoas da natureza enquanto gera renda para sua conservação e para seus moradores $e$ os do entorno". Por meio da visitação pública nas UC, vários objetivos podem ser contemplados, como por exemplo, turismo, recreação, científico, educação ambiental, etc., e isso se consegue com o planejamento das atividades, que são organizadas no Plano de Uso Público (PUP). 
Segundo Nelson (2012), o PUP é um documento oficial, detalhado, que aborda uma variedade de assuntos, devendo estar em consonância com todos os outros planos da UC.

Atualmente, há um aumento da demanda de visitantes em Unidades de Conservação, justificado pelo crescimento do turismo de modo geral. $\mathrm{O}$ PUP se torna necessário e indispensável para que os impactos da visitação nas UC sejam minimizados e/ou mitigados. Uma das formas de aproximação dos visitantes nas Unidades se dá por meio do Ecoturismo.

Em 1994, o documento "Diretrizes para uma Política Nacional de Ecoturismo", publicado pelo Ministério do Meio Ambiente (MMA), estabeleceu um conceito para essa atividade, criando a partir daí um marco importante para o ecoturismo, cujo conteúdo incentiva a conservação ambiental.

[...] um segmento da atividade turística que utiliza, de forma sustentável, o patrimônio natural e cultural, incentiva sua conservação e busca a formação de uma consciência ambientalista através da interpretação do ambiente, promovendo o bem-estar das populações envolvidas (MMA, 1994, p.19).

A publicação desse documento abriu o canal para outras iniciativas, pois além da conservação ambiental, também discute a importância das populações tradicionais nas Unidades de Conservação e a participação destas por meio de atividades não impactantes ou minimamente impactantes, geradas pelo turismo, considerando que tais benefícios chegassem a essas populações, promovendo a melhoria da qualidade de vida das mesmas. Foi o caso da publicação do IBAMA, denominada de "Marco Conceitual das Unidades de Conservação", que discute o uso público nas diferentes categorias de manejo, e que, de certa forma, considera que a visitação em UC é benéfica e promove o desenvolvimento da região onde a Unidade está localizada.

O ecoturismo é uma realidade nas UC no Brasil e no mundo, e para Drumm e Moore (2002, p.15), existem elementos cruciais para o êxito de uma iniciativa dessa atividade:

$\checkmark$ Ter mínimo impacto sobre os recursos naturais de uma área protegida;

$\checkmark$ Envolver os principais interessados (indivíduos, comunidades, ecoturistas, operadores de turismo e instituições governamentais) nas fases de planejamento, desenvolvimento, implantação e monitoramento;

$\checkmark$ Respeitar culturas e tradições locais;

$\checkmark$ Gerar renda sustentável e equitativa para as comunidades locais e para tantos interessados quanto for possível, incluindo operadores de turismo privados; 


\section{$\checkmark$ Gerar renda para a conservação da área protegida; e \\ $\checkmark$ Promover a educação de todos os principais interessados no que diz respeito a seu papel na conservação.}

O ecoturismo pode contribuir para a conservação ambiental por meio de todos esses aspectos relacionados por Drumm e Moore (2002). Pode criar postos de trabalho para as populações residentes, pode promover educação ambiental para os visitantes e também pode gerar fundos para a manutenção das áreas protegidas. Parece a princípio, ser uma receita prática e simples, porém envolve certo grau de amadurecimento dos gestores da conservação, que precisam obedecer a critérios e encontrar a maneira adequada de aplicá-los. Porém, se o desafio é grande, os resultados de um trabalho bem feito são maiores.

Percebe-se, ao conceituarmos ecoturismo, a preocupação com o envolvimento das comunidades em todo o processo de implantação dessa atividade, ao mesmo tempo em que a conservação da área é prioritária. $O$ planejamento do ecoturismo em UC envolve agentes e interesses diferenciados, porém esses dois interesses (conservação e benefícios para as comunidades) devem estar acima de qualquer interesse pessoal ou de determinadas classes que fazem parte do processo.

Ainda que esses interesses estejam em sintonia, não se deve desprezar a ideia de que a implantação de atividades relacionadas ao ecoturismo tem a ver com as estratégias de gestão e mais diretamente com a vontade do gestor da UC, subsidiado de justificativas para inserir ou não a atividade na UC, caso ela não seja uma prioridade apontada por força da lei, como no caso dos Parques, por exemplo. No caso de o gestor adotar a implantação da atividade, o mesmo deve se valer do Plano de Uso Público, caso exista, para realizar as ações indicadas nesse documento de planejamento, que é parte do Plano de manejo.

A participação das comunidades nas atividades turísticas vem por meio do desenvolvimento de diferentes práticas voltadas ao atendimento de visitantes, como a venda de artesanato e de comidas típicas, bem como a prestação de serviços turísticos.

Em 2000, a visitação pública em Unidades de Conservação foi fortalecida com a Lei 9.985, a qual regulamenta o artigo 225 da Constituição Federal e institui o Sistema Nacional de Unidades de Conservação (SNUC) (BRASIL, 2000), restringindo apenas duas categorias de manejo, que são as Estações Ecológicas e as Reservas Biológicas, que limita a visitação justificada somente com finalidade educacional.

A "finalidade educacional", a qual essas categorias de UC estão reservadas, no caso do uso público, encontra justificativa na prática de atividades como o turismo científico e na educação ambiental, esta deve permear todas as atividades desenvolvidas nas Unidades. O controle e regras dessas práticas são feitos pelo Plano de Manejo, e na ausência desse instrumento, por meio de regras editadas pelo órgão gestor da UC. 
A publicação do SNUC reforçou nos órgãos ambientais a necessidade de planejamento de atividades que poderiam ser benéficas para as Unidades de Conservação e gerar renda para a mesma e para as populações envolvidas. Também é uma forma de aproximar a gestão e as populações residentes e do entorno que, a partir de uma perspectiva de geração de renda, se envolvem nas atividades pertinentes, se tornando assim, colaboradores da manutenção dos ecossistemas, já que os mesmos passam a ser a matéria prima do turismo, atividade que pode proporcionar a melhoria da qualidade de vida desses moradores.

A partir dessa perspectiva, os órgãos ambientais responsáveis, em parceria com os interessados no desenvolvimento da atividade turística, passam a elaborar projetos que visem à estruturação da visitação pública nas UC, de forma sustentável. Esse planejamento envolve não somente a infraestrutura física para recebimento de visitantes, como outros pontos importantes, como a capacitação de mão de obra que atenda às perspectivas dos visitantes e, principalmente, o controle do uso e do número de pessoas que adentram a UC.

Segundo Kinker (2002), uma Unidade de Conservação chama atenção para si pelo número de visitantes que recebe, aumentando a necessidade de investimentos. E não se deve perder de vista a cobrança de ingressos, que ajuda na manutenção da mesma.

A relação existente entre a Unidade de Conservação e o visitante, segundo Grahn (2004) é simbiótica, pois uma parte precisa da outra. São muitos os desafios de um gerente ou chefe de UC, e isso exige técnicas e abordagens de acordo com a categoria de manejo da Unidade, objetivando uma experiência de qualidade, proporcionando conhecimento e visando a conservação da área.

As pessoas que visitam as Unidades de Conservação o fazem porque querem adquirir aprendizado e contemplar a natureza, além de entender os motivos pelos quais essas áreas foram criadas.

El turismo en las áreas protegidas tiene beneficios y costos. Esos efectos se entrelazan a menudo de manera compleja y quien se ocupe de la planificación del área protegida tendrá la responsabilidad de maximizar los beneficios minimizando a la vez los costos (EAGLES, 2002, p.23).

Visitantes podem causar impactos positivos ou impactos negativos, e esses impactos podem ser de ordem cultural, social, econômica, no ambiente físico local ou em maior dimensão regional. "[...] uma meta fundamental do turismo sustentável é gerar um equilíbrio mais favorável nesses impactos" (GRAHN, 2004, p.104).

Por mais que os gestores de Unidades de Conservação se esforcem para evitar, os impactos negativos e os riscos ambientais sempre existirão. Portanto, é importante conhecer os riscos da atividade turística e de 
impactos causados por outras formas de uso como a mineração, a urbanização, a agricultura, entre outras.

Correspondendo ao crescimento do turismo, a cada ano cresce a visitação em Unidades de Conservação. Muitos estudos foram e ainda são realizados de forma pontual, de acordo com a necessidade imediata da UC e seus gestores, e hoje se torna necessário 0 estabelecimento de metodologias que estimulem o controle de visitantes, mas que tragam habilidade e ferramentas aos gestores, e que por meio desses instrumentos possam produzir o efeito desejado no visitante, potencializando a visitação pela qualidade da experiência (MMA, 2011).

O MMA lançou em 2006 e aprimorou em 2011 o documento "Roteiro Metodológico para Manejo de Impactos da Visitação", com o objetivo de "estabelecer um marco referencial comum e procedimentos orientadores para o aumento da qualidade da experiência dos visitantes e a proteção dos recursos naturais e culturais das Unidades de Conservação brasileiras" (MMA, 2011, p.11), que consiste na aplicação de métodos, técnicas e habilidades que deverão permear o processo desde o início, até a fase final, com o monitoramento constante da qualidade da visitação, bem como do meio sociocultural e ambiental, e atinge não somente visitantes, mas todos os serviços de apoio na Unidade, como concessionários, permissionários e autorizados.

Para a elaboração desse roteiro metodológico, foram consideradas como referência, além das definições das "Diretrizes para a Visitação em Unidades de Conservação" algumas metodologias utilizadas na determinação de capacidade de suporte. Também foram levadas em consideração as condições das Unidades de Conservação brasileiras e suas realidades, frente às dificuldades constantes com relação à gestão. Essas dificuldades vão desde a falta de infraestrutura para o visitante, ou a precariedade dessa estrutura, onde ela já existe; orçamento insuficiente; e falta de funcionários qualificados.

\section{O Refúgio de Vida Silvestre Metrópole da Amazônia}

Esta pesquisa foi realizada no Refúgio de Vida Silvestre Metrópole da Amazônia, que, conforme o SNUC (BRASIL, 2000), tem o objetivo proteger ambientes naturais e garantir condições para a fauna e a flora se reproduzirem.

Pode ser constituído por áreas particulares, desde que seja
possível compatibilizar os objetivos da unidade com a
utilização da terra e dos recursos naturais do local pelos
proprietários. Havendo incompatibilidade entre os objetivos
da área e as atividades privadas ou não havendo
aquiescência do proprietário às condições propostas pelo
órgão responsável pela administração da unidade para a
coexistência do Refúgio de Vida Silvestre com o uso da
propriedade, a área deve ser desapropriada, de acordo com
o que dispõe a lei.A visitação pública está sujeita às normas
e restrições estabelecidas no Plano de Manejo da unidade,
às normas estabelecidas pelo órgão responsável por sua 
administração, e àquelas previstas em regulamento.Por sua vez, a pesquisa científica depende de autorização prévia do órgão responsável pela administração da unidade e está sujeita às condições e restrições por este estabelecidas, bem como àquelas previstas em regulamento (BRASIL, 2000. p. 15).

Na classificação da IUCN, o REVIS está enquadrado na categoria I Reserva Natural Estricta/Área Natural Silvestre: Área protegida manejada principalmente con fines científicos o con fines de protección de la naturaleza.

\section{Histórico da área e criação da Unidade de Conservação}

Segundo a Lei o 9.985, de 18 de julho de 2000 (SNUC), que regulamenta o art. 225, §1ํㅡㄹ incisos I, II, III e VII da Constituição Federal e institui o Sistema Nacional de Unidades de Conservação da Natureza; os Refúgios de Vida Silvestre (REVIS) são Unidades de Conservação da Natureza do Grupo de Proteção Integral, cujo objetivo é o de proteger ambientes naturais onde se asseguram condições para a existência ou reprodução de espécies ou comunidades da flora e da fauna residente ou migratória.

Áreas particulares são permitidas, porém deve haver compatibilização dos objetivos ou então serão desapropriadas. A visitação pública é permitida, porém está sujeita às normas e restrições estabelecidas no Plano de Manejo e pelo órgão responsável, e as previstas em regulamento. É possível a realização de turismo ecológico e de pesquisas científicas, com autorização do órgão responsável pela administração da UC e àquelas previstas em regulamento, e o desenvolvimento de atividades de educação e interpretação ambiental em contato com a natureza e de recreação.

No trabalho denominado "Áreas Prioritárias para a Conservação, Utilização Sustentável e Repartição de Benefícios da Biodiversidade Brasileira", em 2007, pelo Ministério do Meio Ambiente, a região Nordeste do Estado do Pará foi categorizada como de importância muito alta $e$ extremamente alta, com registro de espécies ameaçadas de extinção e endêmicas.

Nesse contexto, o REVIS foi criado como forma de resguardar a proteção de populações das espécies presentes na Unidade de Conservação que fazem parte da lista de espécies ameaçadas no Estado do Pará, de modo a atender principalmente as conclusões e recomendações desse trabalho, que divulgou a lista de "Espécies Ameaçadas e Áreas Críticas para a Biodiversidade no Pará", divulgada em 2009, considerada a primeira lista vermelha da região amazônica, que identificou um total de 181 espécies ameaçadas, incluídas nas categorias criticamente em perigo (13 espécies), em perigo (47) e vulneráveis (121 espécies). O trabalho foi iniciado em 2008, em parceria entre o Museu Paraense Emílio Goeldi (MPEG), a Conservação Internacional (Cl) e a Secretaria de Estado de Meio 
Ambiente (SEMA). Estas mesmas instituições foram responsáveis pelos trabalhos que resultaram na lista das espécies da flora e da fauna ameaçadas no Estado do Pará, homologada por meio da Resolução COEMA n 54, de 24/10/2007 que consideram que as listas de espécies ameaçadas de extinção são importantes instrumentos de gestão ambiental e de conservação da biodiversidade.

O REVIS está situado na Região Metropolitana de Belém (RMB), possui área de 6.367.27 hectares, e é inteiramente demarcada (considerando que era propriedade particular da antiga Fábrica Pirelli), abrange $6,3 \%$ da área total dos quatro municípios. Fica a $23 \mathrm{~km}$ de Belém, com acesso via terrestre pelo km 14 da BR 316 (Município de Marituba), seguindo por $04 \mathrm{~km}$ pela estrada da Pirelli. Confronta ao Norte com as periferias das sedes dos municípios de Ananindeua, Marituba; ao Sul estende - se por uma faixa de $18 \mathrm{~km}$ ao longo das margens do rio Guamá, entre a foz do igarapé Oriboquinha e a foz do rio Caraparu; a Oeste com o igarapé Oriboquinha e a Área de Proteção Ambiental da Região Metropolitana de Belém (APA Belém), onde está situado o Parque Estadual do Utinga (PEUt), Unidade de Conservação de Proteção Integral que foi criada para garantir a proteção dos lagos Bolonha e Água Preta, principais fontes de abastecimento de água da cidade de Belém e Região Metropolitana; e a Leste com o rio Caraparu.

REVIS Metrópole da Amazônia faz parte de uma área de floresta contínua que soma $1.193,83 \mathrm{~km}^{3}$, e seu território ocupa parte dos municípios de Ananindeua, Marituba, Benevides e Santa Isabel do Pará. Situa-se entre as coordenadas geográficas aproximadas de $01^{\circ} 23^{\prime} 30^{\prime \prime}$ a $01^{\circ} 29^{\prime} 30^{\prime \prime}$ de Latitude Sul e 48 $18^{\circ}$ '00" à $48^{\circ} 22^{\prime} 00^{\prime \prime}$ de Longitude (W.Gr.).

Segundo documentos antigos, a propriedade onde hoje é o REVIS, media 7.787,33 hectares, e foi adquirida na íntegra pelo Governo do Estado, porém, houve a divisão das terras para diferentes finalidades de uso, sendo que a maior parte foi destinada para a criação do REVIS.

Em 2009 a população desses quatro municípios foi estimada em 708.851 habitantes (IBGE, 2009), considerado um alto nível populacional, cuja pressão antrópica atinge diretamente os ecossistemas da Unidade de Conservação (REVIS). Essas populações, em sua maioria vivem em preocupante situação de pobreza, que alcançavam em 1991, segundo dados do IBGE (2009), 58,85\% em Ananindeua e 57,75\% em Benevides/Marituba, visto que essas populações utilizam os recursos naturais como meio de sobrevivência.

A alteração da cobertura vegetal até o ano de 2008 em Ananindeua era de $47 \%\left(86,7 \mathrm{~km}^{2}\right)$, em Benevides de $66 \%\left(124,0 \mathrm{~km}^{2}\right)$, em Marituba de $64 \%\left(65,8 \mathrm{~km}^{2}\right)$ e em Santa Isabel de 74\% (528,8 km²). (IBGE 2009).

Segundo o "Resumo dos Estudos para a criação da UC", a constituição da área tem seu histórico baseado nos seguintes fatos determinantes:

- 1917 com a Carta de Arrematação em nome do Conselheiro Nicolau Martins; 
- 1954 foi comprada pela Empresa Pirelli S.A. e denominava-se Fazenda Guamá, com o propósito de produzir látex, matéria prima para produção de pneus;

- Implementada uma plantação de seringueira (Hevea brasiliensis) e pastagem para a criação de gado bovino;

- 2010 - Decretada Unidade de Conservação de Proteção Integral (Decreto 2211, de 30 de março de 2010). A UC já tem sua logomarca.

O nome Refúgio de Vida Silvestre Metrópole da Amazônia ainda não se popularizou, ficando a UC conhecida popularmente como "Fazenda Pirelli". A área ganhou esse título desde 1954, quando foi comprada pela Empresa Pirelli S.A., para a produção do látex.

Após a incorporação da área ao patrimônio do Estado do Pará, passou-se a cogitar a criação de um núcleo de ecoturismo, tendo sido o assunto bastante debatido entre o poder público e o trade turístico no ano de 1996, chegando inclusive na elaboração de um projeto de arquitetura para a consolidação da estrutura, fato esse que não se consolidou pela mudança no cenário político do Estado, quando da eleição de um novo Governador, de outro partido e com propósitos diferentes aos do primeiro, que projetou a ideia.

O REVIS possui características bastante diferenciadas dentro da mesma área. As comunidades que moram na Vila do Dique, pela entrada oficial, ou seja, pela rodovia BR-316, no município de Marituba, têm acesso a benefícios que não chegam às outras populações ribeirinhas, que moram às margens do rio Guamá e furos e igarapés, como o Taiassuí e Uriboca, que cortam o REVIS.

Segundo o levantamento socioeconômico preliminar, realizado pela equipe de gestão da UC na SEMA, em 2009, existem aproximadamente 28 famílias residentes dentro da $U C$, onde que a maioria reside às margens do rio Guamá e igarapés que cortam o REVIS. Não existe ainda, segundo informações da SEMA, o levantamento de populações residentes na Zona de Amortecimento e no entorno da Unidade.

Para os moradores que já residem há várias gerações, nas comunidades ribeirinhas do REVIS, ao longo do rio Guamá, furos e igarapés, a situação fundiária é menos preocupante, pois, como populações tradicionais que são, utilizam, teoricamente, os recursos naturais de forma sustentável, e os seus objetivos vão ao encontro dos objetivos da criação da UC, respaldando-os para que continuem ocupando as terras, tradicionalmente.

As populações residentes fazem uso dos recursos existentes no REVIS, mesmo depois de sua criação como UC de proteção Integral. Apesar de ser uma UC em área urbana, o extrativismo ainda é praticado pelas pessoas que moram ao longo do rio Guamá, nas áreas ribeirinhas.

A extração do látex da seringueira (Hevea brasiliensis) ou da coleta de urucum (Bixa orellana) e cacau (Theobroma cacao), plantas que foram 
cultivadas na área e que até hoje ainda existem na floresta, são fontes de obtenção de renda para as comunidades residentes. Segundo a SEMA (2009) a pesca também é praticada para subsistência, da mesma forma como o era há dez anos.

O açaí (Euterpe oleracea) é abundante na região e serve de alimento para os moradores, porém, também é alvo de invasores da área, que colhem o fruto e o palmito para comercialização, prática não autorizada pelo órgão responsável pela UC, já que a existência do açaí contribui para a alimentação e reprodução da vida silvestre, objetivo principal da criação da Unidade de Conservação (SEMA, 2009).

A continuidade da exploração dos recursos naturais pelas populações residentes deve ser um ponto a ser discutido e acertado para a minimização dos conflitos. Esses recursos podem ser utilizados sem que haja o seu esgotamento, se for feito de maneira sustentável e com o acompanhamento dos gestores das UC. Além disso, deve-se considerar a relação que os residentes já possuíam com a terra antes da criação da UC, e da dependência dos recursos naturais para a sobrevivência.

[...] a preservação de ecossistemas só é possível em uma visão mais harmoniosa que a sociedade global e as locais devem ter das questões de conservação da natureza. Essa visão é sempre o resultado de uma relação entre ambas e não de seu isolamento forçado. [...] já é sabido que as comunidades locais a serem afetadas pela criação de unidades de conservação devem ser tratadas como aliadas e não adversárias da conservação, e que seu alijamento do processo decisório pode transformá-las, no final, em sérias adversárias de uma preservação da natureza mal concebida e mal desenvolvida (DIEGUES, 1994, p.119).

Considerando a permissão do uso dos recursos pelas populações residentes, conforme a necessidade e a relação tradicional, há que se considerar também, e coibir, os excessos e abusos cometidos e advindos como justificativa dessas mesmas relações. A permissão por parte da gestão da UC, em consentir esse uso, acaba por enfrentar situações de práticas abusivas, que não condizem com os objetivos da Unidade de Conservação e ainda prejudicam a mesma e seus ecossistemas. No caso do REVIS Metrópole da Amazônia, algumas formas de uso depredatório são encontradas, como criação de gado no entorno que por vezes adentra a UC e extração de aterro, os chamados "curvões" na Zona de Amortecimento (SEMA, 2009). Realidades como esses exemplos se encontram rotineiramente em UC no Brasil.

O Refúgio de Vida Silvestre Metrópole da Amazônia, é o maior fragmento de floresta da Região Metropolitana de Belém, e tem em sua área geográfica próxima, outras áreas protegidas. Nessa região, entre outros fragmentos de floresta, estão: Parque Estadual do Utinga (Estadual); APA da Região Metropolitana de Belém (Estadual); APA da Ilha do Combu (Estadual); Terra Quilombola do Abacatal. 
Além desses, foram identificados, na Região Metropolitana de Belém (RMB), mais 154 fragmentos florestais, com tamanhos que variam entre $1 \mathrm{e}$ 393 hectares. Para Ferreira (2010, p. 361), "O tamanho, a forma geométrica e a distância entre os fragmentos de vegetação podem influenciar inúmeros processos ecológicos, tais como mortalidade, migração e colonização de plantas e animais". Ferreira (2010) se refere a espaços como o Parque Estadual do Utinga (PEUt), porém não cita, ainda em sua obra, o Refúgio de Vida Silvestre, criado em 2010 e que faz conexão direta com o PEUt, com possibilidades de fluxo dos animais entre as duas UC. Foi constatado, pelos pesquisadores do Museu Goeldi que contribuíram nas pesquisas do presente trabalho, uma semelhança da avifauna residente e migratória entre as duas Unidades.

O PEUt, bem como os outros fragmentos florestais identificados na RMB, faz parte do Centro de Endemismo Belém (CE). Esses fragmentos merecem atenção por serem os últimos remanescentes de floresta nessa região. Para Vieira e Almeida (2006, p. 95), a floresta amazônica é a última das florestas tropicais, com grande extensão, e a maior parte destas florestas está no Brasil.

O Estado do Pará abriga quatro Centros de Endemismo, sendo Guiana, Xingu, Tapajós e Belém. As maiores ameaças a essas áreas são a perda de habitat, a degradação e a fragmentação causada pelo desmatamento e extração seletiva de madeira. A intensidade de uso da terra e de desflorestamento não está homogeneamente distribuída entre estes centros, sendo o Centro de Endemismo Belém o mais ameaçado, dada a ocupação mais antiga das frentes pioneiras. A perda de floresta pode ser usada como um indicador de vulnerabilidade para cada área de endemismo (VIEIRA e ALMEIDA, 2006, p.96).

O Centro de Endemismo Belém (CEB), localizado entre as coordenadas geográficas $00^{\circ} 30^{\prime} 00^{\prime \prime}$ e $06^{\circ} 00^{\prime} 00^{\prime \prime}$ de latitude Sul e $44^{\circ}$ ' $00^{\prime}$ $00^{\prime \prime}$ e $50^{\circ} 00^{\prime} 00^{\prime \prime}$ de longitude WGr, possui uma área de $243.000 \mathrm{~km}^{2} \mathrm{e}$ localiza-se a Leste do Pará e a Oeste do Maranhão. Nele estão contempladas áreas protegidas, sendo, até 2006, 27 UC e 14 Terras Indígenas. 147 municípios do Pará e do Maranhão fazem parte do $\mathrm{CE}$ (VIEIRA e ALMEIDA, 2006).

Em que pese todo o incentivo à criação de Unidades de Conservação, como forma de garantir a proteção da biodiversidade, sabe-se que a meta estabelecida em 2002 pela Conferência das Partes da Convenção sobre a Biodiversidade para alcançar uma redução significativa da taxa de perda de biodiversidade até o ano de 2010 não foi cumprida. Mesmo com o crescimento substancial das redes de áreas protegidas nas últimas décadas, não se conseguiu travar a crise. Entretanto, o estabelecimento de novas áreas protegidas não é o único meio para se alcançar a conservação em muitos lugares onde a biodiversidade está ameaçada, e muitas vezes nem 
se aplica a todos. Assim, além de análises de lacunas identificando áreas ou espécies que necessitam de mais ou menos conservação, é importante também a procurar outras soluções talvez mais práticas para a proteção da biodiversidade através da criação de iniciativas locais de conservação. A observação de aves pode ser um desses instrumentos (PUHAKKA et al., 2011) (Traduzido pela autora).

\section{Observação de aves}

Observar aves é um hábito muito comum e que pode começar muitas vezes de forma bastante desinteressada, quando se coloca comedouros e bebedouros no quintal de casa ou mesmo nas sacadas dos apartamentos nas cidades, com a intenção de atrair as aves, por meio da comida fácil. Esse comportamento inocente é discutível no meio acadêmico, porém causa prazer às pessoas, pois atrai esses animais para uma exibição mais aproximada.

[...] na observação de aves o indivíduo tem a oportunidade de ser expectador e cúmplice do grande espetáculo da natureza, sentindo o desenrolar da vida em toda a sua espontaneidade e plenitude. Nessa tarefa, muitos já conseguiram oferecer importantes subsídios à sua comunidade e à Ciência.Um efeito colateral dessa atividade é a compreensão da natureza como um todo, favorecendo o desabrochar do desejo de preservação ambiental nos participantes. Dessa maneira, eles se tornam elementos indispensáveis na luta pela nossa própria sobrevivência como espécie. Só por isso já é válida a existência de um observador de aves (ALMEIDA, 2003, p.1).

Observar aves pode fazer parte de um estilo de vida, de pessoas que têm prazer em estar no meio natural, mas é parte de um movimento que cresce cada vez mais no Brasil. A observação de aves permite, para quem observa, presenciar acontecimentos inusitados e emocionantes sobre as aves, e isso traz como consequência o envolvimento e comprometimento das pessoas com a conservação ambiental.

Essa contribuição para a ciência também pode ser um excelente instrumento de gestão para áreas protegidas, pois, por meio de informações sobre a existência de espécies, se chega à cadeia alimentar, tornando importante a manutenção de ecossistemas. Um gestor de Unidade de Conservação que tem informações sobre a variedade e o número estimado de espécies residentes ou migratórias na área, pode propor um plano de conservação, justificando a manutenção de determinadas espécies de vegetação baseado nessa cadeia ecossistêmica e, a partir daí, projetar atividades para a UC, que favoreçam a manutenção das espécies.

Incentivar a observação de aves em Unidades de Conservação pode trazer benefícios diretos para a própria Unidade, através da educação ambiental dos usuários de forma geral e das comunidades residentes no interior e entorno, o que promove a importância do estado de conservação e preservação. 
Há mais de 9.000 espécies de aves no mundo. Segundo o Comitê Brasileiro de Registro Ornitológico (CBRO), o Brasil conta com 1.832 espécies de aves. Sigrist (2008) registrou 1.330 espécies somente na Amazônia brasileira. Novaes e Lima (2009) registraram 490 espécies para a região da Grande Belém (PA), ou seja, quase um terço das aves da Amazônia podem ser avistadas nesta região.

Para Mourão (1999, p.1-6), "identificar aves nada mais é do que, por meio da observação criteriosa, descobrir qual sua família e espécie, procedimento cujo resultado é a grande recompensa do observador de aves - colecionador de avistagens". Para a identificação, devem-se observar alguns elementos, como por exemplo: tamanho; forma; cores; vocalização; tipo de voo; habitat; comportamento, entre outros, que devem ser anotados em uma caderneta de campo. A partir desses elementos, a identificação final deve ser feita com a ajuda de um guia de campo, com ilustrações ou desenhos das espécies avistadas.

Com base nos detalhes da ave e observando outros aspectos sobre o ambiente em que se encontra, é possível fazer anotações quando se avista esses animais. Mourão (1999) sugere o seguinte roteiro para anotação, por ocasião da identificação das aves: Em que habitat / bioma / ecossistema ela está?; Qual a estação do ano?; Qual seu tamanho?; Qual sua forma ou silhueta?; Como são seus pés e pernas?; Como é seu bico?; Quais suas cores e marcas especiais?; Quais as características de pouso / vôo?; Qual seu comportamento?; Como é sua vocalização?

As aves, segundo o senso comum, são conhecidas com nomes que variam a cada região de ocorrência e como os habitantes denominam as mesmas em suas regiões. Esses nomes comuns são dados em função de alguma característica do animal, como por exemplo, o habitat, a cor, o canto, o comportamento, etc. Geralmente encontram-se casos de denominação de uma mesma espécie, conhecidos por nomes diferentes, dependendo da região. A nomenclatura, que é a denominação universal da ave, é escrita em latim. A composição do nome científico é formada por pares de nomes, ou por três nomes, e também são inspirados em características das aves, como descrito acima. Encontram-se muitos casos em que são incluídos nos nomes das aves, o nome de quem a descobriu ou o nome de alguém como homenagem (MOURÃO, 1999).

O Brasil é considerado atualmente o segundo país com maior diversidade de aves no mundo, e que essa atividade reúne milhares de adeptos. Para se observar aves e ter precisão na identificação, além de ter paciência e boa vontade, é preciso ficar atento a algumas técnicas e ter posse de alguns equipamentos como: Binóculos com aumento entre 8 a 10 vezes ( 8 X 50); Máquina fotográfica; Gravador; Luneta; Guia de Campo; Fotos ou vídeos; Roupas adequadas; Gravação sonora ou imitação do canto; Caderneta de campo; Acuidade visual e auditiva; Comportamento adequado.

A observação de aves, ou birding, ou ainda birdwatching, como também é conhecida, cresce a cada dia na América do Sul, pois no resto do mundo essa atividade já atingiu grande parte do Planeta. Estima-se que 
mais de 60 milhões de pessoas observam aves no mundo todo (PIVATTO, 2013). Essa é uma atividade que efetivamente colabora com a evolução da ciência, pois além de confirmação de avistamentos de espécies, um dos grandes desafios e emoções da atividade é a descoberta de novas espécies, enriquecendo listas pelo mundo inteiro, e sua popularização fortalece a conservação ambiental. É prazerosa, divertida e de grande valia para a ciência e pode ser um excelente instrumento de gestão em áreas protegidas, já que a sua prática contribui para a conservação ambiental.

A observação de aves é uma atividade de lazer e representa um segmento com muitas possibilidades econômicas e sociais para um destino turístico, que muitas vezes se forma em função de uma lista de aves interessantes, raras, em risco, endêmicas, etc. É rentável, e é uma das atividades de turismo relacionadas com a natureza, com a maior taxa de crescimento (MOURÃO, 1999). O observador de aves, ou birdwatcher ou birder é a pessoa que se dedica a essa atividade, a princípio como passatempo e como forma de se aproximar da natureza, e torna-se um grande colaborador das ciências, através de confirmações dos registros de aves. Graças a pessoas que cultivam esse passatempo, muitas espécies estão sendo preservadas e sua vida resguardada da extinção.

Com relação ao número de observadores de aves no mundo, segundo Mourão (1999) a maioria dos observadores de aves está baseada nos Estados Unidos, Canadá e Inglaterra (mais de um milhão de observadores de aves), com informações sobre o aumento do número de observadores na África do Sul, Alemanha, Austrália, Espanha, França, Japão e Holanda seguidos se sensível aumento em países como Argentina, Equador, México e Malásia.

Pivatto et al. (2007) acrescenta dados sobre essa atividade, informando que no período entre 1970-80 surgem os primeiros clubes de observadores de aves que promoviam atividades isoladas, com poucos interessados. Em 1997, com o mercado ainda imaturo para a nova atividade, surge o primeiro Encontro de Observadores de Aves e Turismo no Rio de Janeiro, com pouca participação. Nesse período aumenta a demanda para cursos sobre observação de aves, já como resultado da divulgação, mesmo que ainda insipiente. Em consequência, surgem novos roteiros e destinos especializados.

Surge então o Primeiro Encontro Brasileiro de Observação de Aves (Avistar Brasil), em 2006 reunindo pela primeira vez instituições de ensino, operadoras de turismo, editoras, fotógrafos, associações de observadores de aves, estudantes e outros interessados no segmento (proliferação de clubes de observadores de aves e de novos roteiros pelo Brasil). Esse evento vem se repetindo todos os anos, com uma participação cada vez maior, bem como vem se multiplicando em vários lugares do país, com atividades segmentadas dentro do próprio evento, diversificando assim o público e aumentando a frequência. Ainda não existem dados oficiais sobre a observação de aves e seus rendimentos. Estimou-se que mais de 600 turistas tenham vindo ao Brasil em 2005 especificamente para observar aves, movimentando cerca de um milhão de dólares (PIVATTO et al., 2007). 
A Observação de Aves é um segmento do Turismo que tem necessidades diferentes das outras modalidades, e por isso necessita de atenção especial, em se tratando de infraestrutura e outros itens. Segundo Mourão (1999, p.2-5), para se considerar um destino de qualidade e confiável, são necessários alguns indicadores:

$\checkmark$ Aves interessantes e informações (guias de campo; listas de aves, atualizadas, contendo informações sobre sazonalidade e diversidade dos habitats visitáveis; guias especializados, bilíngues, apoiados por guias locais (mateiros), capazes de identificar as aves comuns, endêmicas, especiais e raridades);

$\checkmark$ Condições de acesso a habitats; infraestrutura e facilidades (Restaurantes e lanchonetes, hospedagem, sanitários, abrigos sombreados e protegidos de insetos, etc.);

$\checkmark$ Preços razoáveis (compatíveis com a qualidade do destino).

Algumas normas devem ser seguidas, de forma geral, para quem desenvolve atividades no meio natural. Essas normas também se aplicam aos observadores de aves, em qualquer que seja o ambiente da observação. Segundo Mourão (1999, p.1-2), "em qualquer situação de conflito entre a fauna e os interesses dos observadores, o bem-estar das aves e o respeito por seus habitats devem ser prioridade".

Puhakka et al. (2011), apontam no resultados de pesquisas, algumas das maiores fraquezas como: infraestrutura de turismo e serviços prestados para os turistas; problemas no acesso devido à infraestrutura rodoviária; a falta de alojamento; falta de bons guias; segurança; terrorismo, a criminalidade ou corrupção; problemas de saúde, como intoxicação alimentar ou doenças tropicais; falta de confiabilidade dos operadores de turismo locais; condições naturais ou geográficas, tais como distâncias dentro do país; problemas de conservação especificamente com perda de habitat; poucas oportunidades para a participação local; a falta de guias locais, e/ou a falta organização mínima entre eles.

No Brasil não existem estatísticas formais para a atividade, porém uma iniciativa do Encontro Brasileiro de Observação de Aves (AVISTAR 2012), através do $1^{\circ}$ Censo Brasileiro de Observação de Aves, foi realizado em ambiente virtual e contou com a colaboração de aproximadamente 2.560 interessados em observação de aves.

Segundo o censo, a maioria dos entrevistados pertence ao sexo masculino, têm entre 35 e 54 anos de idade; residem no Estado de São Paulo; têm ensino superior completo. $70,9 \%$ tentam identificar uma ave ao vê-la; conhecem entre 21 e 100 espécies de aves; observam ou fotografam aves há mais de 10 anos; $62,8 \%$ conhecem as aves pelos nomes regionais; um terço dos entrevistados jamais visitaria uma área sem cuidados ambientais; e $61,2 \%$ consideram que a existência de UC é uma motivação para visitar uma área. De 1.800 entrevistados, somente 19,2\% conhecem a Amazônia. 
A observação de aves é considerada uma atividade especial para o turismo, pois os adeptos dessa modalidade, em geral, são pessoas com um elevado nível de informação sobre o meio ambiente e que respeitam a vida silvestre. Apesar de não ter ainda a representatividade econômica de acordo com o potencial da atividade, vem crescendo bastante e proporcionado oportunidades de negócios.

\section{As aves do Refúgio de Vida Silvestre}

O REVIS possui um perímetro de $62 \mathrm{~km}^{2}$, e grande parte de sua área encontra-se em recuperação, pelo uso da terra antes da criação da UC, ter sido destinado para o plantio de seringueiras (Hevea brasiliensis) e como pasto para gado bovino.

Dessa forma, com a floresta ainda em estado de recuperação, devese indicar para a observação de aves, os locais que se encontram em estado mais adiantado de regeneração, onde aumentam as oportunidades de avistamentos de espécies que requerem ambiente em bom estado de preservação, pela pouca perturbação existente oriunda da parte externa da UC, como é o caso do capitão-do-mato (Lipaugus vociferans), e do Arapaçubarrado-do-nordeste (Dendrocolaptes certhia medius). Esses locais estão situados na parte mais densa da floresta e no centro do REVIS. As áreas de várzea, localizadas nas beiras de igarapés também são adequadas para a observação, fato comprovado por ocasião das investidas a campo, em busca de vestígios de espécies de avifauna. Dessa forma, há previsão para estruturar esses locais, para proporcionar melhores condições para os visitantes com interesse específico em observar aves.

Em algumas áreas dentro da UC, mesmo não estando em excelente estado de preservação, como é o caso da entrada oficial do REVIS (BR 316), pode-se avistar várias espécies com certa facilidade, como é o caso do Araçari-de-bico-branco (Pteroglossus aracari)e outras espécies.

Para Novaes e Lima (2009), há o registro de 490 espécies de avifauna na região da Grande Belém. Esse número, aliado a uma infraestrutura adequada para receber observadores de aves, pode ser um componente indutor de um fluxo turístico especializado, que além de promover o REVIS, pode gerar outros benefícios para as comunidades da UC e do entorno, seja por meio do incentivo para a implantação da atividade de observação de aves, ou para a sensibilização de moradores e visitantes da Unidade.

Confirmando o estudo realizado por Puhakka et al. (2011) e Pivatto (2007), que retratam a opinião dos observadores de aves com relação à necessidade de infraestrutura nos locais apropriados para observação, como torres e passarelas, e a carência de guias especializados em aves, para completar os pacotes oferecidos por operadoras que trabalham com 0 segmento, percebe-se que estes fatores ainda são entraves que dificultam a vinda desse público especializado para a região. Essa lacuna tem relação direta com a timidez com que esse tipo de turismo acontece no Estado, e essa necessidade vem sendo percebida por especialistas ornitólogos que, segundo informações da equipe que auxiliou nesta pesquisa, já se inicia a 
criação de um grupo de observadores de aves no ambiente do Museu Goeldi, porém com a participação de alguns amantes da natureza que residem em Belém e que estão, aos poucos, se agregando a esse grupo que vem crescendo. Esses "especialistas" têm interesse no desenvolvimento da atividade no REVIS, bem como estendê-la para os fragmentos florestais da Região Metropolitana.

Considerando que um dos principais motivos para a criação da Unidade de Conservação foi a publicação da "Lista de espécies da flora e da fauna ameaçadas do Estado do Pará", homologada através da Resolução 054/2007, do Conselho Estadual de Meio Ambiente (COEMA), em 24/10/2007, com 31 espécies de avifauna que em situação de risco, lista devidamente categorizada pela União Internacional para a Conservação da Natureza - IUCN. Esse estudo foi realizado em parceria entre o Museu Paraense Emílio Goeldi (MPEG), a Conservação Internacional $(\mathrm{Cl})$ e a Secretaria de Estado de Meio Ambiente (SEMA).

Por ser uma atividade considerada de baixíssimo impacto ambiental, a atividade, uma vez implantada na Unidade de Conservação pode promover a inclusão social no entorno da mesma. O benefício é percebido imediatamente ao morador do entorno do REVIS, principalmente para os que estiverem diretamente envolvidos como condutores de observadores de aves, como mateiros ou em outra ocupação pertinente que, ao proteger 0 local, terá em conta que estará protegendo sua fonte de renda.

\section{Espécies de aves de interesse para a observação no REVIS}

Algumas espécies que ocorrem no REVIS estão na lista de espécies ameaçadas do Estado do Pará. O Quadro 1 mostra a lista de espécies avistadas no REVIS no período de 31/03/2012 a 02/05/2013

Quadro 1: Lista de espécies avistadas no REVIS no período de 31/03/2012 a 02/05/2013.

Table 1: List of species sighted in REVIS the period from 31/03/2012 to 02/05/2013.

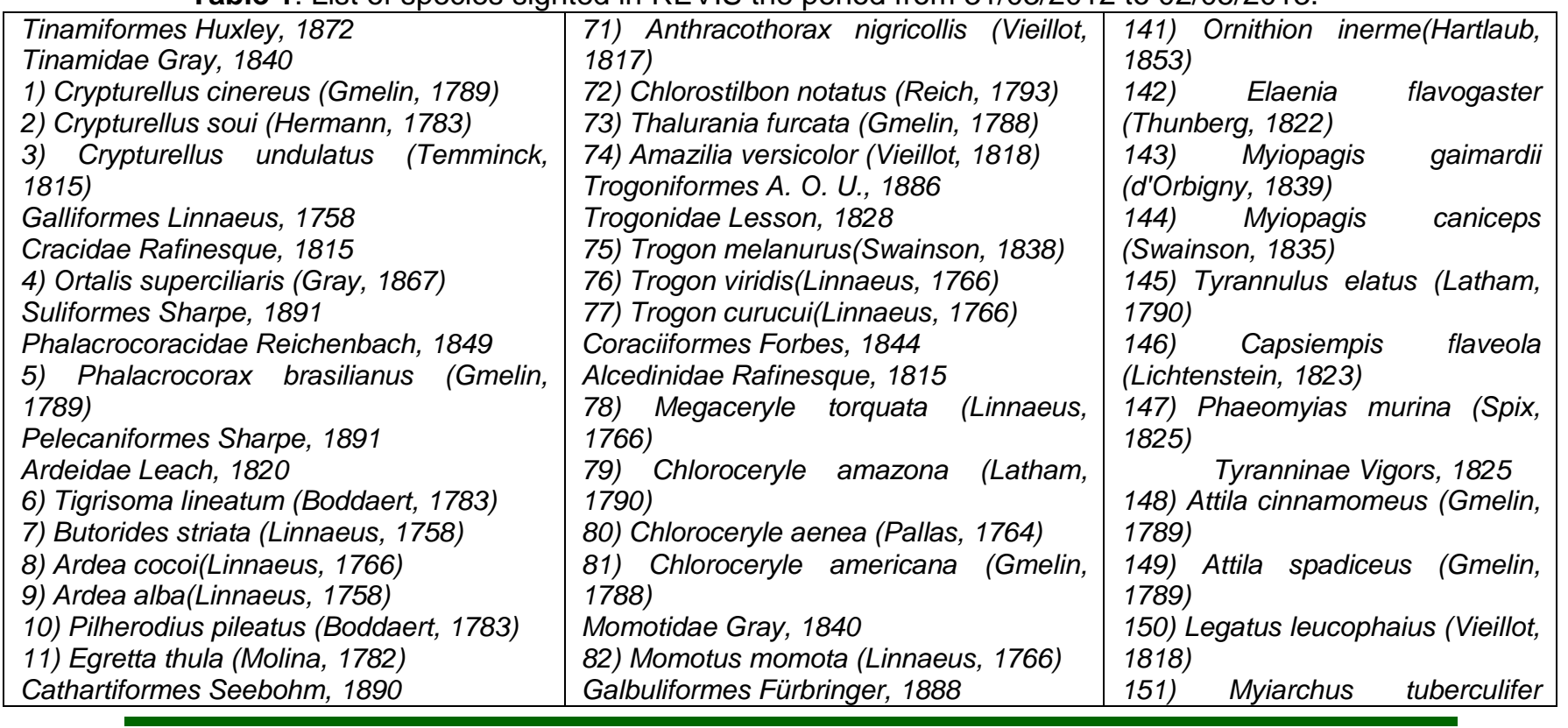




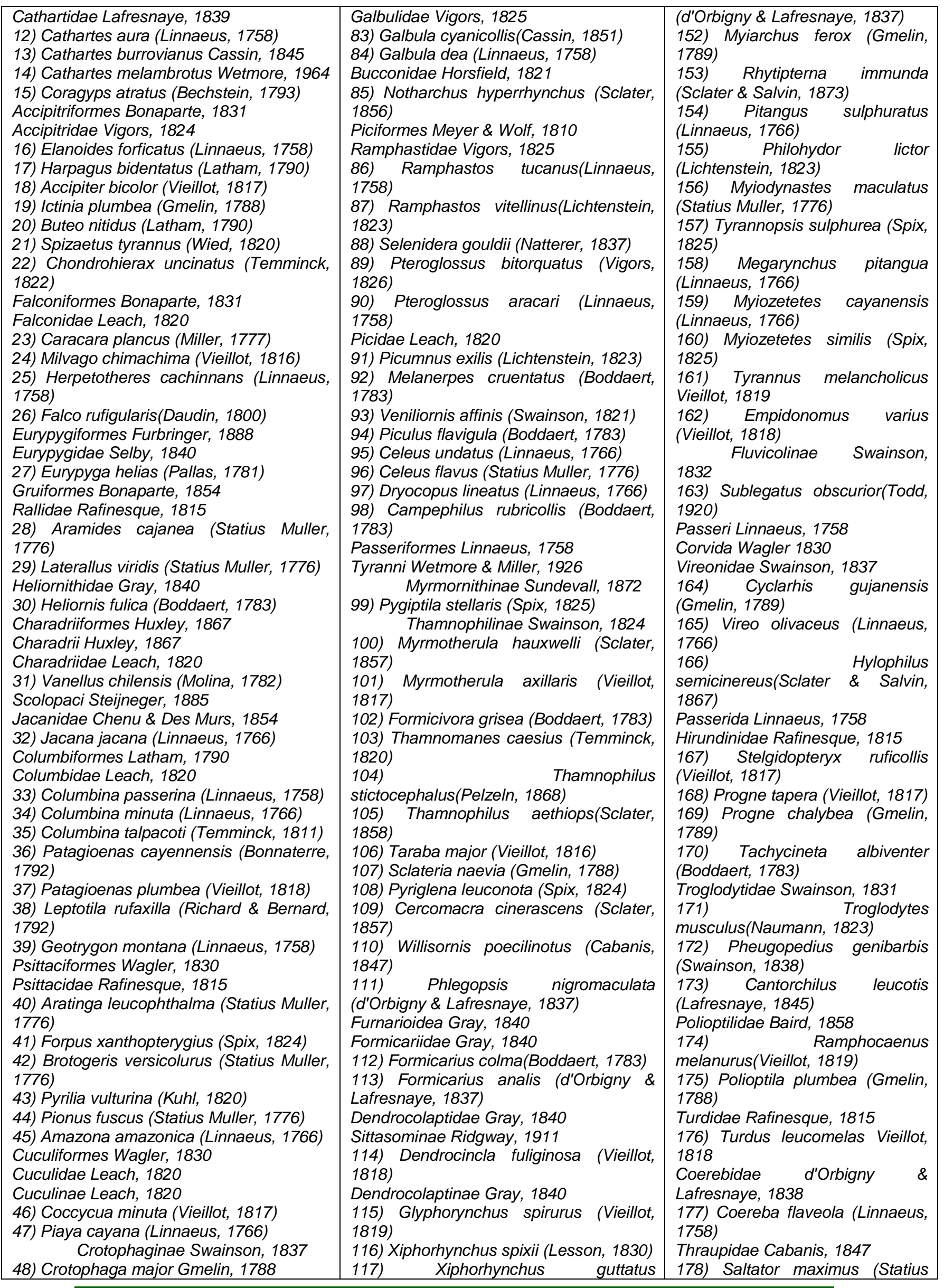


49) Crotophaga ani Linnaeus, 1758

50) Guira guira (Gmelin, 1788)

Taperinae Verheyen, 1956

Strigiformes Wagler, 1830

Tytonidae Mathews, 1912

Strigidae Leach, 1820

51) Megascops choliba (Vieillot, 1817)

52) Megascops usta (Sclater, 1858)

53) Lophostrix cristata (Daudin, 1800)

54) Pulsatrix perspicillata (Latham, 1790)

55) Strix virgata (Cassin, 1849)

56) Glaucidium hardyi Vielliard, 1990

57) Athene cunicularia (Molina, 1782)

Caprimulgiformes Ridgway, 1881

Nyctibiidae Chenu \& Des Murs, 1851

58) Nyctibius grandis (Gmelin, 1789)

59) Nyctibius griseus (Gmelin, 1789)

Caprimulgidae Vigors, 1825

60) Hydropsalis nigrescens (Cabanis, 1848)

61) Hydropsalis albicollis (Gmelin, 1789)

62) Hydropsalis parvula (Gould, 1837)

Apodiformes Peters, 1940

Apodidae Olphe-Galliard, 1887

63) Chaetura brachyura (Jardine, 1846)

64) Tachornis squamata (Cassin, 1853)

Trochilidae Vigors, 1825

Phaethornithinae Jardine, 1833

65) Glaucis hirsutus (Gmelin, 1788)

66) Threnetes leucurus (Linnaeus, 1766)

67) Phaethornis ruber (Linnaeus, 1758)

68) Phaethornis bourcieri (Lesson, 1832)

69) Phaethornis superciliosus (Linnaeus,

1766)

Trochilinae Vigors, 1825

70) Campylopterus largipennis (Boddaert, 1783)
(Lichtenstein, 1820)

Furnariidae Gray, 1840

118) Dendrocolaptes certhia medius

(Todd, 1920)

119) Xenops minutus (Sparrman, 1788)

Synallaxinae De Selys-Longchamps, 1839 (1936)

120) Synallaxis gujanensis (Gmelin, 1789)

Piprinae Rafinesque, 1815

121) Pipra fasciicauda(Hellmayr, 1906)

122) Pipra rubrocapilla(Temminck, 1821)

123) Lepidothrix iris (Schinz, 1851)

124) Manacus manacus (Linnaeus, 1766)

Ilicurinae Prum, 1992

125) Chiroxiphia pareola (Linnaeus, 1766)

Oxyruncinae Ridgway, 1906 (1831)

126) Onychorhynchus coronatus (Statius Muller, 1776)

Laniisominae Barber \& Rice, 2007

127) Schiffornis turdina (Wied, 1831)

Tityrinae Gray, 1840

128) Tityra semifasciata (Spix, 1825)

129) Pachyramphus marginatus (Lichtenstein, 1823)

Cotinginae Bonaparte, 1849

130) Lipaugus vociferans (Wied, 1820)

131) Querula purpurata (Statius Muller, 1776)

Pipromorphinae Wolters, 1977

132) Mionectes oleagineus (Lichtenstein, 1823)

133) Mionectes macconnelli (Chubb, 1919)

Rhynchocyclinae Berlepsch, 1907

134) Tolmomyias poliocephalus (Taczanowski, 1884)

135) Tolmomyias flaviventris (Wied, 1831)

Todirostrinae Tello, Moyle, Marchese \& Cracraft, 2009

136) Todirostrum maculatum

(Desmarest, 1806)

137) Poecilotriccus sylvia (Desmarest, 1806)

138) Myiornis ecaudatus (d'Orbigny \& Lafresnaye, 1837)

139) Lophotriccus galeatus (Boddaert, 1783)

1856

Tyrannidae Vigors, 1825

Elaeniinae Cabanis \& Heine,

140) Zimmerius gracilipes (Sclater \&

Salvin, 1868)

Muller, 1776)
179) Tachyphonus rufus
(Boddaert, 1783)
180) Ramphocelus carbo (Pallas,
1764) Lanio penicillatus (Spix,
181) La mexicana
1825) Tangara
182)
(Linnaeus, 1766)
$183)$

183) Tangara episcopus

(Linnaeus, 1766)

184) Tangara palmarum (Wied, 1823)

185) Dacnis cayana (Linnaeus, 1766)

Emberizidae Vigors, 1825

186) Ammodramus aurifrons (Spix, 1825)

187) Volatinia jacarina (Linnaeus, 1766)

188) Sporophila nigricollis (Vieillot, 1823)

189) Sporophila minuta (Linnaeus, 1758)

190) Sporophila angolensis (Linnaeus, 1766)

191) Arremon taciturnus (Hermann, 1783)

Cardinalidae Ridgway, 1901

192) Caryothraustes canadensis (Linnaeus, 1766)

193) Cyanoloxia cyanoides (Lafresnaye, 1847)

Parulidae Wetmore, Friedmann, Lincoln, Miller, Peters, van Rossem, Van Tyne \& Zimmer 1947

194) Geothlypis aequinoctialis (Gmelin, 1789)

Icteridae Vigors, 1825

195) Psarocolius viridis (Statius Muller, 1776)

196) Psarocolius bifasciatus (Spix, 1824)

197) Cacicus haemorrhous (Linnaeus, 1766)

198) Cacicus cela (Linnaeus, 1758)

199) Icterus

(Linnaeus, 1766)

200) Molothrus bonariensis (Gmelin, 1789)

Fringillidae Leach, 1820

201) Euphonia violacea (Linnaeus, 1758)

Passeridae Rafinesque, 1815

202) Passer domesticus (Linnaeus, 1758) 


\section{Situação atual e proposições para o desenvolvimento do ecoturismo (observação de aves) no REVIS}

Uma das pretensões deste trabalho de pesquisa é de que o mesmo possa subsidiar o Plano de Uso Público (PUP) do REVIS com informações relacionadas ao ecoturismo, com foco principal na atividade de observação de aves, e dessa forma, contribuir para a conservação da área.

Partiu-se do princípio que, para se elaborar um PUP, não existe fórmula ou receita, pois cada situação e cada Unidade de Conservação tem suas características peculiares e deve-se seguir as diretrizes do órgão gestor (NELSON, 2012).

No caso do Estado do Pará, o Programa de Uso Público é o $5^{\circ}$ programa trabalhado no Plano de Manejo, e nele constam como subprogramas: 1) Recreação, lazer e interpretação ambiental; 2) educação ambiental; e 3) Ecoturismo. Os objetivos do Plano de Uso Público nas UC do Pará, segundo o órgão gestor ambiental do Estado são:

[...] definir as ações de planejamento, implementação, promoção e ordenamento das atividades de uso público da UC, segundo sua categoria de manejo, de modo a proporcionar ao visitante uma experiência de qualidade no meio ambiente natural (SEMA, 2009, p. 43).

Para a concretização dessas exigências, a SEMA (2009) recomenda a elaboração de regulamentos e normas de segurança para os visitantes, bem como de normas de uso pelo visitante e mecanismos de monitoramento da visitação, além de recomendar também a implementação das infraestruturas de apoio à visitação, abertura e manejo de trilhas ecológicas para uso de visitantes.

A partir do levantamento bibliográfico e de campo, percebe-se a necessidade da elaboração de um Plano de Uso Público voltado ao desenvolvimento do ecoturismo como um todo, porém levando-se em consideração o foco principal deste estudo, que é a observação de aves, aproveitando os resultados produzidos nesta pesquisa, que subsidiam o início da atividade na UC.

$\mathrm{Na}$ proposta desta pesquisa estão apontados itens para a operacionalização, como contribuição para o PUP da UC, a fim de dotar a UC da capacidade de receber observadores de aves e demais turistas.

Com base no esquema de elaboração de um PUP, conforme sugerido por Nelson (2012), serão detalhadas a seguir as possíveis ações a serem implementadas, com adaptações feitas a partir da realidade local do REVIS Metrópole da Amazônia. Para isso, foram considerados dois momentos da observação: 1) Inventário e diagnóstico, onde devem constar as informações básicas da Unidade de Conservação e, 2) Prognóstico e estratégias, ou ações sugeridas, que recomendam as ações para se chegar a um resultado concreto das ações propostas.

Dessa forma, serão enumerados alguns pontos considerados críticos e que demandam ações em curto e médio prazo, para iniciar o processo de captação de observadores de aves e ecoturistas tradicionais e outros visitantes. 
Quadro 2: Situação e Estratégias.

\section{SITUAÇÃO ATUAL}

Table 2: Scenarios and Strategies.

\begin{tabular}{|c|c|}
\hline $\begin{array}{l}\text { ACESSO E } \\
\text { TRANSPORTES }\end{array}$ & $\begin{array}{l}\text { O REVIS está situado na Região Metropolitana de Belém, no município de } \\
\text { Marituba, com fácil acesso pela BR-316, a aproximadamente } 1 \text { hora de } \\
\text { carro, do centro da capital. Essa distância é um fator positivo para a } \\
\text { atividade de observação de aves na UC, pois turistas de outras localidades } \\
\text { têm as facilidades de hospedagens e outros serviços turísticos de uma } \\
\text { cidade grande, sem a necessidade de alojamento e dormitório na Unidade } \\
\text { ou próximo a ela. A situação da estrada vicinal entre a BR-316 e a entrada } \\
\text { oficial do REVIS não se encontra em boas condições de trafegabilidade, } \\
\text { porém o acesso é garantido, mesmo com certa dificuldade. Essa vicinal é } \\
\text { habitada e atualmente os moradores depositam lixo na via pública. Pode-se } \\
\text { chegar à Unidade também por via fluvial, saindo de alguns portos situados à } \\
\text { Avenida Arthur Bernardes, em Belém, porém não há transporte regular, } \\
\text { ficando o acesso, geralmente, limitado às populações ribeirinhas. }\end{array}$ \\
\hline $\begin{array}{l}\text { PONTOS DE } \\
\text { ENTRADA }\end{array}$ & $\begin{array}{l}\text { A UC possui oficialmente uma única entrada, que fica localizada na Estrada } \\
\text { da Pirelli, no município de Marituba. Nessa entrada há uma guarita com um } \\
\text { posto de serviço do Batalhão de Polícia Ambiental (BPA), com guarda } 24 \\
\text { horas por dia, onde geralmente seis policiais são plantonistas a cada turno. } \\
\text { Esta é somente a entrada oficial e não a única entrada que dá acesso à UC, } \\
\text { que não tem muro de isolamento e é cercada por vários bairros da RMB, } \\
\text { além da área ribeirinha, com } 18 \mathrm{~km} \text { de extensão, ao longo do rio Guamá. } \\
\text { Existem alguns pontos críticos de entradas clandestinas, como é caso da } \\
\text { rua Agrovila São Pedro, que termina na divisa com a UC, por onde entram } \\
\text { pessoas de moto ou de bicicleta, para caçar e cometer outros ilícitos. }\end{array}$ \\
\hline $\begin{array}{l}\text { RECURSOS } \\
\text { NATURAIS, } \\
\text { CULTURAIS E } \\
\text { HISTÓRICOS }\end{array}$ & $\begin{array}{l}\text { O REVIS detém mais de seis mil hectares de floresta, com remanescentes } \\
\text { de floresta primária, capoeiras, várzeas e igapós; além de muitas espécies } \\
\text { de mamíferos, insetos e uma rica avifauna. Esse levantamento está pronto e } \\
\text { deve ser atualizado por ocasião da elaboração do Plano de manejo da } \\
\text { Unidade, o que, segundo a SEMA.Com relação a atrativos culturais e } \\
\text { históricos, estão presentes no interior da UC, bem como no seu entorno, na } \\
\text { comunidade quilombola de Abacatal, representações de marcos histórico- } \\
\text { culturais, por meio de ruinas de engenhos e outros vestígios remanescentes } \\
\text { do tempo da escravidão. }\end{array}$ \\
\hline
\end{tabular}

ESTRATÉGIAS

Contratar empresa para realizar a manutenção das estradas internas à UC, considerando os 62 quilômetros de perímetro. Algumas ações que deverão ser desencadeadas pela Gerência da UC em parcerias com instituições governamentais ou não, para melhorar o acesso com relação à situação da estrada principal, bem como na realização de campanhas de educação ambiental, coleta seletiva, reflorestamento e paisagismo da via, entre outras ações necessárias. Tratando-se de uma Unidade de Conservação localizada na Região Metropolitana de Belém, os observadores de aves deverão se deslocar em condução locada pelo grupo (carro com tração) até a entrada da UC. Alguns trechos dentro da Unidade poderão ser trafegados nesse tipo de veículo, porém, é possível os da Unidade poderão ser trafegados nesse tipo
deslocamentos a pé, a partir da guarita de entrada.

A rua Agrovila São Pedro deve ser fechada com muro (aproximadamente 30 metros de abertura). Deve haver rondas permanentes do BPA em toda a área. Além desse ponto clandestino de acesso, onde há uma certa facilidade para sanar o problema, fechando com muro, há outros pontos que não há possibilidade de fechamento, e, para esses, há que se ter uma ronda diária e permanente do BPA, pois há muita facilidade de cometimento de ilícitos nesses pontos.

Com relação aos atrativos culturais e históricos, deve ser feito um levantamento mais detalhado da arquitetura antiga existente no interior da Unidade, o que remete à história da Fazenda Pirelli, bem como estudos e projetos visando à revitalização de algumas dessas estruturas, para aproveitamento no PUP da Unidade, como centros de visitação e outros espaços de apoio administrativo e aos visitantes. Um atrativo cultural que deve ser trabalhado turisticamente é o Quilombo Abacatal, uma Terra Quilombola reconhecida por Lei, situada na Zona de Amortecimento do REVIS, com mais de 300 hectares, cujos moradores são parceiros da SEMA e, segundo essa instituição, começam a desenvolver ações em parceria, inclusive projetos de turismo para os quilombolas. Nessas terras existem ruínas de igrejas e outras estruturas de engenho. O modo de vida tradicional dos 


\begin{tabular}{|c|c|c|}
\hline & & quilombolas também pode agregar valor turístico ao produto. \\
\hline & SITUAÇÃO ATUAL & ESTRATÉGIAS \\
\hline $\begin{array}{l}\text { INFRAESTRU- } \\
\text { TURA }\end{array}$ & $\begin{array}{l}\text { Atualmente não há nenhuma infraestrutura adequada para } \\
\text { os visitantes. O BPA, que mantém uma equipe de policiais } \\
\text { no local, em regime de plantão } 24 \text { horas, também não tem } \\
\text { uma estrutura de apoio adequada. Existem também } \\
\text { alguns prédios abandonados que estão em estado crítico } \\
\text { e sem condições de aproveitamento para nenhuma } \\
\text { estrutura de apoio à UC. No que diz respeito, } \\
\text { especificamente, à infraestrutura para observação de } \\
\text { aves, foi realizado durante o trabalho de pesquisa, o } \\
\text { levantamento da área, dando ênfase aos pontos onde } \\
\text { poderão ser construídos os equipamentos que darão } \\
\text { suporte aos observadores, bem como poderáservir de } \\
\text { apoio a outros visitantes não especializados.Foram } \\
\text { identificados pontos de observação, considerando-se a } \\
\text { diversidade de ecossistemas, priorizando áreas onde a } \\
\text { floresta está mais conservada, aumentando assim a } \\
\text { possibilidade de avistamentos. }\end{array}$ & 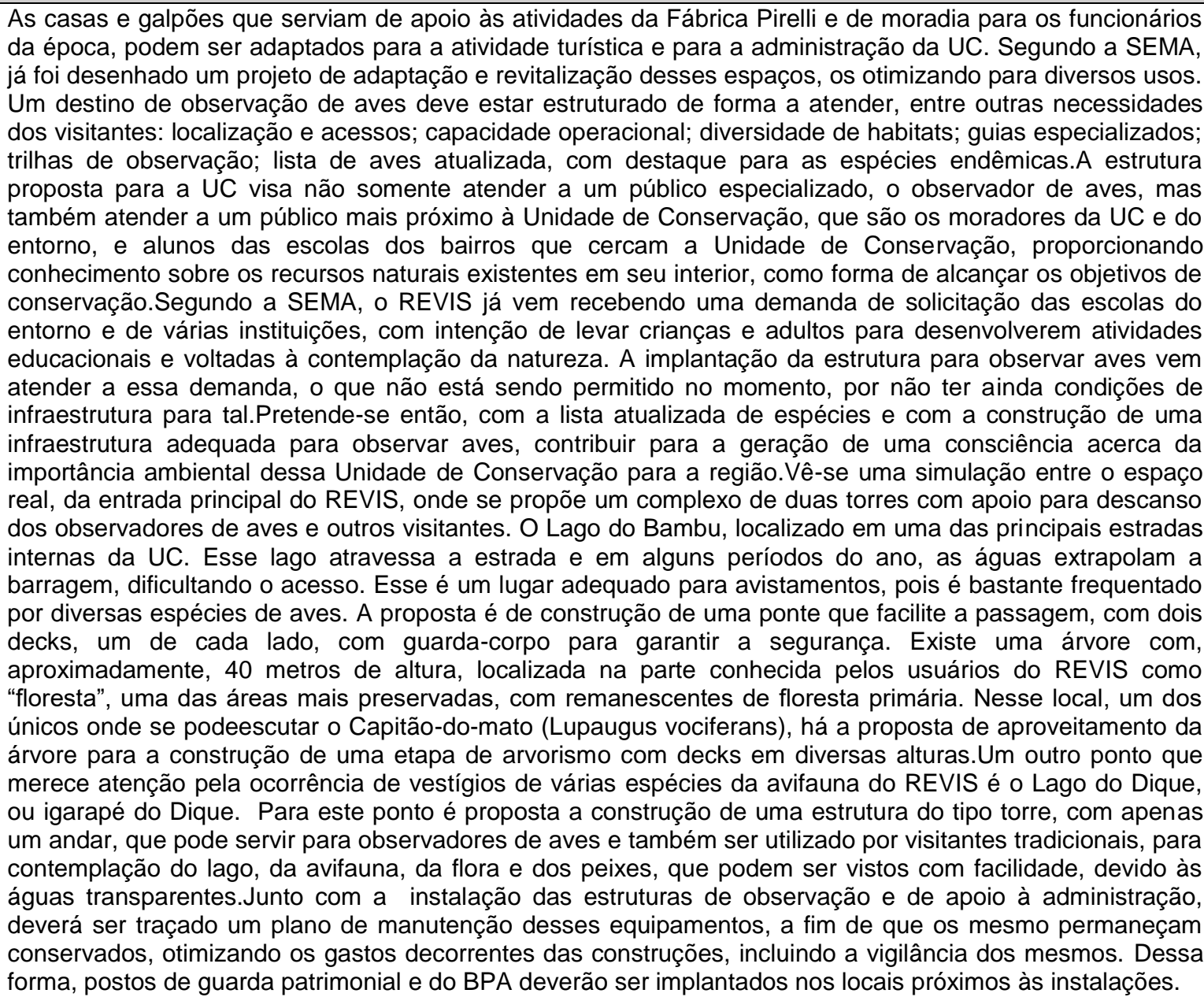 \\
\hline
\end{tabular}




\section{SITUAÇÃO ATUAL}

\section{PERFIL DOS}

VISITANTES

REVIS não tem ainda, em seu cotidiano, uma visitação turística, estando o uso restrito para pesquisadores que utilizam a UC como local de pesquisa para diversos interesses científicos. Também fazem uso da Unidade, alguns militares das forças armadas, em treinamentos táticos e a prática de educação física.

\section{INGRESSOS E} OUTROS ITENS RELACIONADOS ÀS FINANÇAS

Não são cobradas taxas para esses usos, sendo exigido apenas, segundo a SEMA, uma autorização para a realização dessas atividades diversas, ocasião em que 0 órgão ambiental comunica as normas para o uso dos visitantes. Segundo o órgão, as regras de uso serão oficializadas brevemente em um documento legal, editado pela Secretaria.

\section{\begin{tabular}{l|l} 
SINALIZAÇÃO & Não há sinalização turística no REVIS e nem placas que
\end{tabular}} indiquem se tratar de uma Unidade de Conservação.

\section{MEIOS DE}

DIVULGAÇÃO

Não há divulgação sistematizada sobre a UC em nenhum meio de comunicação. A área da Unidade ainda é conhecida como "Pirelli". Segundo a SEMA, está sendo produzido um material informativo que será impresso ainda neste ano de 2013, para a distribuição ao público em geral. No site da Secretaria de Meio Ambiente é possível visualizar informações resumidas sobre a Unidade. A divulgação informal ainda é o meio pelo qual a UC vem sendo divulgada.

\section{ESTRATÉGIAS}

A visitação no REVIS Metrópole da Amazônia não deve segmentar público, porém direcionar para os amantes da natureza e de atividades de lazer ao ar livre.Devem ser realizadas pesquisas junto aos órgãos oficiais de turismo de Belém e do Estado (BELEMTUR, SETUR e PARATUR), a fim de identificar o perfil dos visitantes no Estado do Pará e seus interesses principais, bem como os tipos de estrutura utilizada por cada público-alvo. Os observadores de aves são um público à parte, que possuem necessidades diferenciadas, necessitam de condutores locais especializados em aves e utilizam horários diferentes dos demais turistas. Por essa razão, ações diferenciadas devem ser adotadas, como por exemplo a instalação de torres de observação, e a permissão para entrada na Unidade em horários diferenciados aos de rotina.

Nas UC do Estado do Pará, de modo geral, ainda não há cobrança de nenhuma taxa de visitação, porém essa cobrança, prevista pelo SNUC, é aconselhável para a manutenção da Unidade, mas antes da sua institucionalização, devem ser construídas as estruturas para atender as necessidades dos visitantes. A partir daí deve-se elaborar estudos para a cobrança de taxas para a entrada na UC, o que seria apenas um caminho para a entrada de recursos que venham contribuir para a sustentabilidade financeira do REVIS. Esse ainda é um tema bastante polêmico de discussão, pois uma Unidade de Conservação que seja absolutamente sustentável, do ponto de vista das finanças, é o desejo de órgãos gestores e gerentes ou chefes de UC. Não é apenas o aumento da receita que importa na conservação ambiental, mas sim, de que forma é utilizada esssa receita. A receita que entra na UC deve ser utilizada em comum com todas as áreas pertinentes, como planejamento estratégico, recursos humanos, marketing, entre outras. No caso do REVIS, certamente a cobrança de ingressos não deverá ser aplicada de imediato, é preciso que sejam investidos os recursos de Compensação Ambiental na estruturação da Unidade, para que funcione e seja efetivada a sua gestão. A partir desse investimento, deve-se então pensar na cobrança de ingressos para a composição de um Fundo de manutenção da UC.

Placas educativas e outros tipos de sinalização também são facilidades que os observadores admiram e que funcionam, para o público em geral, como instrumento de educação ambiental.Existe um projeto de sinalização, segundo a SEMA, com placas que deverão ser distribuídas em toda a área da Unidade.Sugerese esses recursos para as áreas onde serão implantadas as estruturas físicas no REVIS.

Para incrementar a visita turística e a observação de aves, sugere-se que sejam confeccionados folders, cartilhas, adesivos e, direcionando para observadores de aves, pequenos guias de campo com as aves do REVIS, bem como pranchas com as principais espécies. Sugere-se um link no site da SEMA, com a lista de aves da Unidade.Além desse instrumento de divulgação, sugere-se que seja confeccionado um mapa do REVIS, com a sinalização dos locais prováveis de avistamentos das espécies existentes na UC, com o objetivo de otimizar o tempo dos observadores, bem como para se tomar medidas de conservação das espécies. 


\begin{tabular}{|c|c|c|}
\hline & SITUAÇĀO ATUAL & ESTRATEGIAS \\
\hline COMUNIDADES & $\begin{array}{l}\text { As comunidades existentes dentro do REVIS são: Vila do Dique, Vila Três } \\
\text { Marcos, Ponta Negra e Santo Amaro, esta última localizada no rio } \\
\text { Taiassuí, no entorno imediato da UC. Foi iniciado um estudo } \\
\text { socioeconômico das comunidades residentes no REVIS e, segundo a } \\
\text { SEMA, esse estudo ainda está em andamento. }\end{array}$ & 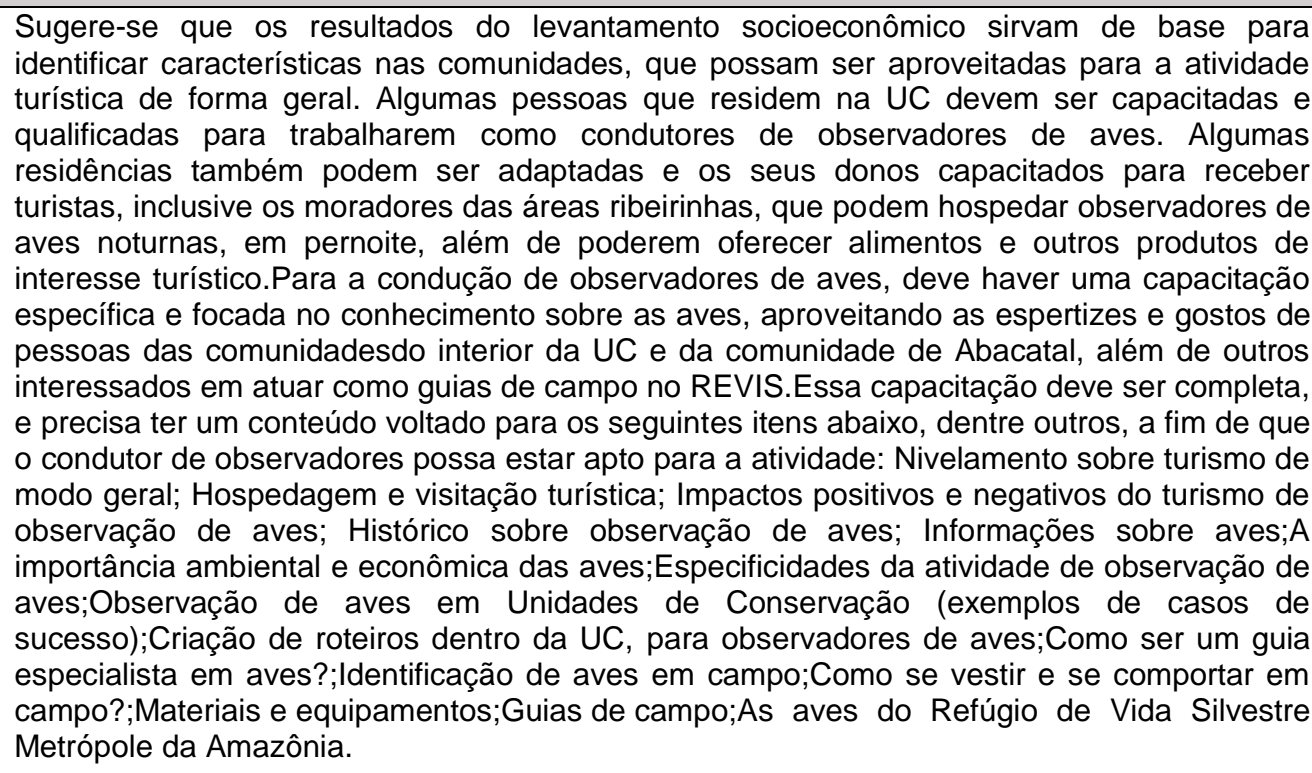 \\
\hline $\begin{array}{l}\text { RECURSOS } \\
\text { HUMANOS NA } \\
\text { ADMINISTRAÇÃ } \\
\text { O DA UC }\end{array}$ & $\begin{array}{l}\text { A Gerência do REVIS funciona no prédio da Diretoria de Áreas Protegidas } \\
\text { (DIAP), cuja sede está localizada no Parque Estadual do Utinga, na } \\
\text { Avenida João Paulo, s/n, a aproximadamente } 20 \mathrm{~km} \text { do REVIS. A equipe } \\
\text { de gestão é composta de três servidores ( } 1 \text { turismóloga - gerente, } 1 \\
\text { engenheira agrônoma e um contador, todos técnicos em gestão de meio } \\
\text { ambiente) do quadro fixo da Secretaria de Meio Ambiente. A equipe conta } \\
\text { com o apoio do BPA (6 policiais por turno) na Unidade, que fazem a ronda } \\
\text { diária nos pontos mais críticos da UC. Não existem estagiários ou outros } \\
\text { colaboradores. }\end{array}$ & $\begin{array}{l}\text { Contratar servidores e estagiários para auxiliar nos trabalhos relacionados à gestão da UC, } \\
\text { para atender ao público visitante. No caso do turismo de observação de aves, os servidores } \\
\text { devem ser capacitados de acordo com as necessidades do público, e qualificados com as } \\
\text { informações sobre as aves da Unidade, e dos locais estratégicos de avistamentos. }\end{array}$ \\
\hline
\end{tabular}




\begin{tabular}{|c|c|c|}
\hline & SITUAÇĀO ATUAL & ESTRATÉGIAS \\
\hline TRILHAS & $\begin{array}{l}\text { Toda a extensão da UC é cortada por trilhas, anteriormente utilizadas pela } \\
\text { administração da Fazenda Pirelli, para coletar e escoar a produção da } \\
\text { fazenda e, posteriormente, por seringueiros para a coleta do látex e por } \\
\text { outros moradores do interior e do entorno da Unidade, em busca de } \\
\text { produtos da floresta. Esse complexo de caminhos não é sinalizado. } \\
\text { Atualmente, praticamente todas as trilhas são usadas por seringueiros que } \\
\text { residem no REVIS, porém não há manutenção das mesmas, e isso foi } \\
\text { comprovado por ocasiãa da pesquisa que resultou neste trabalho, pela } \\
\text { dificuldade em adentrar a floresta, com exceção de algumas em bom } \\
\text { estado de conservação. }\end{array}$ & $\begin{array}{l}\text { Deve ser realizado um levantamento de dados em todo o sistema de trilhas, como: inventário } \\
\text { de flora e fauna, topografia, extensão, condições para caminhar, grau de dificuldade, } \\
\text { capacidade de suporte, necessidade de obras como pontes e outras. Ao final desse } \\
\text { levantamento, dever ser elaborado um mapa turístico do REVIS, que poderá auxiliar o } \\
\text { visitante na sua localização. Uma sinalização deve ser adotada para que as trilhas possam } \\
\text { ser utilizadas com fins turísticos e interpretativos, ao mesmo tempo em que dá segurança } \\
\text { aos visitantes. }\end{array}$ \\
\hline SEGURANÇA & $\begin{array}{l}\text { Por estar cercado por bairros populosos de um lado, e de outro lado por } \\
\text { águas do rio Guamá, e por não ser isolado por cercas ou muros, o REVIS } \\
\text { é alvo de invasões para a retirada de recursos naturais como madeira, } \\
\text { palmito, açaí (euterpe oleracea), látex, caça e pesca predatórias. Junta-se } \\
\text { a isso a deficiência de contingente da Polícia Ambiental e da fiscalização } \\
\text { da SEMA, o que resulta em um aumento da vulnerabilidade da área. }\end{array}$ & $\begin{array}{l}\text { O envolvimento das comunidades do interior e do entorno da UC é um importante } \\
\text { instrumento que pode auxiliar no monitoramento e na denúncia da prática de crimes } \\
\text { ambientais. Sugere-se a formação de agentes ambientais voluntários para fortalecer as } \\
\text { açãesda SEMA e do BPA na preservação do meio ambiente. Segundo a SEMA, há um Plano } \\
\text { de Monitoramento e Fiscalização que foi elaborado em conjunto com as UC da Região } \\
\text { Metropolitana de Belém e o BPA, para operacionalizar um monitoramento eficaz da área, } \\
\text { diminuindo assim a ocorrência de ilícitos. }\end{array}$ \\
\hline ARTESANATO & $\begin{array}{l}\text { Nenhuma das comunidades produz artesanato. Segundo a SEMA, um } \\
\text { inventário socioeconômico está sendo realizado, com o intuito de se } \\
\text { conhecer a realidade das comunidades bem como o potencial das cadeias } \\
\text { produtivas da UC. Após esse levantamento será traçado um cronograma } \\
\text { de capacitações voltadas para as comunidades e interessados em } \\
\text { participar da cadeia do turismo. }\end{array}$ & $\begin{array}{l}\text { Recomenda-se o levantamento das cadeias produtivas que podem ser fomentadas com o } \\
\text { uso de matérias primas da natureza, sem o comprometimento dos recursos naturais e } \\
\text { aproveitando o potencial cultural e histórico da região. Entende-se que, a partir dos dados } \\
\text { levantados sobre a observação de aves na UC, pode-se pensar em incluir vaŕas atividades } \\
\text { relacionadas, como principalmente a produção de artesanato com recursos não madeireiros, } \\
\text { e a condução de visitantes, o que pode ser uma fonte de renda e oportunidades de negócios } \\
\text { para os moradores locais.Como o látex da seringueira (Hevea brasiliensis) é um produto } \\
\text { ainda extraído na UC, mesmo após a sua criação, pode-se aproveitá-lo na fabricação de } \\
\text { artesanato de borracha, em forma de aves e outros animais, capacitando os seringueiros } \\
\text { para otimizar e diversificara a produção e agregar valor ao produto. Oburiti (Mauritia flexuosa) } \\
\text { também é abundante na região e sua palha pode ser transformada em artesanato com } \\
\text { aceitação já comprovada por turistas. }\end{array}$ \\
\hline
\end{tabular}




\section{Conclusão}

A Região Metropolitana de Belém possui considerável diversidade de avifauna e esse potencial deve ser aproveitado para o incremento da atividade ecoturística voltada para a observação de aves.

A criação de Unidades de Conservação vem colaborando para a conservação da biodiversidade no Brasil, e não é diferente no estado do Pará. Otimizar essas áreas para o uso devido e responsável é obrigação do poder público, que conta com a participação da sociedade civil organizada. Manter Unidades de Conservação no Brasil, sem a presença humana é um desafio e foge da realidade, pois sabe-se que a presença humana está em quase todas as UC, sendo de proteção integral ou de uso sustentável.

Cabe aos gestores a tarefa de transformar essas áreas protegidas em espaços democráticos e utilizáveis, respeitando os princípios para os quais elas foram criadas. Associar a preservação ao uso da UC é utilizar o bom senso e agir de acordo com a realidade dessas áreas. São grandes as possibilidades de desenvolver atividades ligadas ao turismo sustentável e o envolvimento das comunidades é importante para o sucesso dessa empreitada.

A observação de aves pode ser um caminho para a conservação e para a melhoria da qualidade de vida de pessoas que se relacionam com o Refúgio de Vida Silvestre Metrópole da Amazônia. O planejamento adequado, a participação e o envolvimento da comunidade podem trazer resultados positivos.

Os resultados ora apresentados, sob a forma da lista atualizada de espécies da avifauna e como sugestões propostas para a implementação da atividade na UC,é apenas o início de um trabalho onde os benefícios podem chegar a todos, bem como para a conservação ambiental. As pesquisas relacionadas à atividade turística precisam de mais estudos e envolvimento real das comunidades residentes, bem como dos parceiros do poder público, responsável pela Unidade de Conservação.

Segundo a SEMA, a Unidade passa pela instalação do Conselho Consultivo, em sua fase final de formação, e as comunidades estão envolvidas por meio das representações sociais e institucionais se mostram favoráveis ao envolvimento das comunidades nas atividades pertinentes à UC. Conforme depoimento de representantes da SEMA, as comunidades querem que o turismo aconteça na região, e querem ser protagonistas dessa atividade, por acreditar no potencial que a região possui. Esse envolvimento é fundamental para o desenvolvimento da atividade turística na Unidade. Além das comunidades envolvidas, as instituições com assento no Conselho da Unidade, assim como de Organizações Não Governamentais (ONGs) que se estabeleceram na região com o objetivo de primar pela qualidade da existência da UC, podem e devem participar da atividade turística. Sabe-se que cada instituição possui interesses os mais diversos e peculiares, porém o interesse maior deve ser o da melhoria da qualidade do ambiente, bem como da vida das pessoas envolvidas. 


\section{Referências bibliográficas}

ALMEIDA, S. A Observação de aves. Disponível em <http://www.ao.com.br>, 2003.

BRASIL. Ministério do Meio Ambiente. Lei Federal № 9.985 de 18/07/2000. Regulamenta o artigo 225 da Constituição Federal e institui o Sistema Nacional de Unidades de Conservação. Brasília, DF, 2000.

DIEGUES, A.C.S. O Mito Moderno da Natureza Intocada. Hucitec. São Paulo, 1994.

DRUMM, A.; MOORE, A. Desenvolvimento do Ecoturismo: Um Manual Para Profissionais de Conservação. Volume I: Introdução ao Planejamento de Ecoturismo. The Nature Conservancy. Virginia (EUA), 2002.

EAGLES, P.F.J., McCOOL S.F.; HAYNES, C.D. Turismo sostenible en áreas protegidas: Directrices de planificación y gestión. Preparado para el Programa de las Naciones Unidas para el Medio Ambiente, la Organización Mundial del Turismo y la UICN - Unión Mundial para la Naturaleza. Organización Mundial del Turismo. Programa de las Naciones Unidas para el Medio Ambiente. UICNUnión Mundial para la Naturaleza. Capitán Haya, 4228020 Madrid - España. 2002.

FERREIRA, L.V.; PAROLIN, P.; MUÑOZ, S.H.; CHAVES, P.P. O efeito da fragmentação e isolamento florestal das áreas verdes da Região Metropolitana de Belém. Pesqui Bot, v. 63, p.p.357-67, 2012.

GRAHN, A. Administração de Visitantes em Unidades de Conservação. In: Ecoturismo: Práticas Para Turismo Sustentável. Editora Vale/UniNorte. AM, 2004. P. 101-136.

IBGE.

Disponível

em:

http://www.ibge.gov.br/home/estatistica/populacao/estimativa2009/>. Acesso em: 12 out. 2013.

KINKER, S. Ecoturismo e Conservação da Natureza em Parques Nacionais. Editora Papirus. Campinas, SP, 2002.

MAGRO, T.C. Impactos do Uso Público em uma Trilha noPlanalto do Parque Nacional do Itatiaia. Tese de Doutorado em Ciências da Engenharia Ambiental. Escola de Engenharia de São Carlos, Universidade de São Paulo, 1999.

MMA / Grupo de Trabalho Interministerial. Diretrizes para uma Política Nacional de Ecoturismo. Brasília. 1994.

MOURÃO, R.M.F. Observação de Aves. In: Manual de Melhores Práticas para - Ecoturismo. Programa MPE/FUNBIO. Fundo Brasileiro Para a Biodiversidade, Rio de Janeiro, 1999.

NELSON, S.P. Uso Público nas Unidades de Conservação. In: CASES, M.O. (org.). Gestão de Unidades de Conservação: Compartilhando Uma Experiência de Capacitação. Realização: WWF/lpê - Instituto de Pesquisas Ecológicas. Organizadora: WWF Brasil, Brasília, 2012, p. 215-236.

NOVAES, F.C.; LIMA, M.F.C. Aves da Grande Belém. Municípios de Belém e Ananindeua, Pará. 2ª edição. Museu Paraense Emílio Goeldi. Belém, 2009. 
PIVATTO, M.A.C.; SABINO, J.; FAVERO, S.; MICHELS, I.L. Perfil e viabilidade do turismo de observação de aves noPantanal Sul e Planalto da Bodoquena (Mato Grosso do Sul) segundo interesse dos visitantes. Revista Brasileira de Ornitologia. V.15, n.4: p.p. 520-529, 2007.

PIVATTO, M.A.C. Curso de Planejamento e Manejo do Uso do Público em Unidades de Conservação: Práticas e oportunidades para observação de aves (Birdwatching). Fortalecimento e implantação da gestão do uso público nas Unidades de Conservação do Rio deJaneiro. INEA/Bionúcleo. Rio de janeiro, 2013.

PUHAKKA, L.; SALO, M.; SÄÄKSJÄRVI, I.E. Bird Diversity, Birdwatching Tourism and Conservation in Peru: A Geographic Analysis. Department of Biology, University of Turku, Turku, Finland. Published November 23, 2011.

SEMA. Roteiro Metodológico para Elaboração de Plano de Manejo das Unidades de Conservação do Estado do Pará. Secretaria de Estado de Meio Ambiente. Belém, 2009.

VIEIRA, I.C.G.; ALMEIDA, A.S. Caracterização da cobertura vegetal e uso da terra, enfatizando os fragmentos florestais no Centro de Endemismo Belém. Relatório de pesquisa. Museu Paraense Emílio Goeldi, 2006.

Maria do Perpétuo Socorro Rodrigues de Almeida: Secretaria de Estado de Meio Ambiente e Sustentabilidade do Pará, Belém, PA, Brasil.

E-Mail: caxiuana@gmail.com

Link para o currículo Lattes: http://lattes.cnpq.br/1186892185962305

Mirleide Chaar Bahia: Universidade Federal do Pará, Belém, PA, Brasil.

E-mail: cici.w@gmail.com.

Link para o currículo Lattes: http://lattes.cnpq.br/6052323981745384

Sherre Prince Nelson: Centro Universitário do Norte, Manaus, AM, Brasil.

E-Mail: snelsonspn@gmail.com

Data de submissão: 08 de julho de 2016

Data de recebimento de correções: 21 de julho de 2016

Data do aceite: 21 de julho de 2016

Avaliado anonimamente 